\title{
TEXTO Y TEXTUALIDAD EN LA TEORÍA SEMIÓTICA DE JANOS PETÖFI: LA CONSTITUCIÓN MODAL DEL INTÉRPRETE COMO CRITERIO ÚLTIMO DE LA TEXTUALIDAD
}

\author{
Adrián BERTORELLO \\ Universidad de Buenos Aires \\ adrianbertorello@fibertel.com.ar
}

Resumen: En este trabajo se expone la teoría semiótica de J. Petöfi sobre la significación y el texto. El eje central de la argumentación es proponer una alternativa al concepto de texto de la hermenéutica de P. Ricoeur para quien el criterio de textualidad está en la escritura como exteriorización del discurso. Por el contrario, J. Petöfi propone un criterio extra-textual, a saber, una determinada secuencia discursiva puede ser considerada como un texto en función de la competencia deíctico-modal del intérprete. Asimismo, el trabajo presenta uno de los supuestos ontológicos de la semiótica textual: el isomorfismo estructural entre la realidad extralingüística, la coherencia textual y la mente.

Abstract: This study shows J. Petöfi's theory about signification and text. It is based on the proposal of an alternative for the concept of text of herme- 
neutics of P. Ricoeur, who said that text criterion appears in writing as exteriorization of discourse. On the other hand, Petöfi proposes an extra-textual criterion, i.e., a determined discursive sequence that can be considered a text according to the deictic-modal competence of the interpreter. Likewise, the study shows one of the ontological assumptions of textual semiotics: structural isomorphism between extralinguistic reality, textual coherence and mind.

Palabras Clave: Texto. Coherencia. Significación. Realidad.

Key words: Text. Coherence. Signification. Reality.

Este trabajo tiene como objetivo presentar la teoría de J. Petöfi sobre la significación y el texto como una alternativa a la posición de la hermenéutica de P. Ricoeur. La idea principal del trabajo radica en que el criterio último de textualidad, es decir, el parámetro por el que una determinada secuencia discursiva (escrita u oral) es considerada como un texto no es otra cosa que la competencia deíctico-modal del intérprete que con sus esquemas mentales confiere significado a dichas secuencias. Esta posición tiene a su vez un presupuesto ontológico que J. Petöfi no desarrolla, pero menciona explícitamente. En efecto, entre los esquemas mentales y la realidad existe un isomorfismo que es el que posibilita la coherencia de un texto. Lamentablemente J. Petöfi no desarrolla estas implicaciones ontológicas. Sólo se limita a decir que la realidad extralingüística posee una configuración determinada.

Como se puede apreciar, la teoría semiótica del texto establece un criterio extra-textual (la mediación de la subjetividad humana) para definir la noción de texto. Esta posición desafía y pone en tela de juicio la concepción de Ricoeur, para quien el criterio de textualidad radica en la escritura: «Llamamos texto a todo discurso fijado por la escritura. Según esta definición, la fijación por la escritura es constitutiva del texto mismo» (Ricoeur, 2001: 127). Esta definición se funda en un determinado aspecto del discurso escrito que Ricoeur denomina «el carácter espiritual de la escritura» (Ricoeur, 2001: 173) (Ricoeur, 1998: 44). Cuando el discurso oral se fija mediante la escritura se produce un acto que tiene dimensiones ontológicas cuyo sentido es una deshistorización. En efecto, el texto escrito elimina la condición contextual histórica del discurso. El acto de enunciación fáctico (lo que Ricoeur llama «el acontecimiento del discurso») se supera en el plano del significado. La teoría 
semántica de Ricoeur es deudora de la fenomenología de Husserl. El significado escrito tiene el carácter de la idealidad, es decir, significa independientemente de las condiciones subjetivas, sociales o históricas de producción (Ricoeur, 1988: 103). La escritura produce, de este modo, una obra que tiene un carácter semántico autónomo. De ahí que su criterio de textualidad, a diferencia del de Petöfi, sea intratextual.

Ahora bien, si el texto es un producto semánticamente autosuficiente, entonces la subjetividad no cumple ningún rol en la constitución de su sentido. Esta última afirmación tiene que ser precisada. Ricoeur restringe a dos funciones el papel que cumple la subjetividad en la constitución semántica del texto: a) en virtud del carácter ideal del significado escrito el análisis estructural es la estrategia de lectura que logra explicar la autonomía semántica; y b) una vez establecido el sentido objetivo mediante el análisis estructural (Ricoeur, 2001: 154), al lector histórico sólo le queda apropiarse del texto, es decir, incorporar esa red significativa a sus propios horizontes de expectativas. De este modo se puede apreciar claramente que si la red semántica del texto escrito tiene el estatus ontológico de la idealidad fenomenológica y si sólo el análisis estructural es capaz de fijar la objetividad del mismo, entonces el estatus de la subjetivad correlativa a ese tipo de significado tiene que tener un carácter transhistório. Es, por decirlo con la expresión de Th. Nagel, la perspectiva que mira desde ningún lugar (Nagel, 1996: 81-99). El concepto de apropiación, que expresa la condición histórica de la subjetividad, cumple un papel irrelevante en la constitución semántica del texto. Sólo expresa el efecto que la idealidad semántica produce en el lector.

Antes de comenzar con esta breve exposición de la semiótica de Petöfi querría hacer una breve alusión sobre su pensamiento. Petöfi denomina al marco teórico desde donde aborda el problema del texto semiotic-text-theoretical framework (Petöfi-Olivi, 1989: 190-191). Este marco se apoya sobre dos ideas fundamentales: en primer lugar, los textos son realidades complejas que, para ser estudiados, requieren un punto de vista integrador. Dicho negativamente: la perspectiva puramente lingüística no logra dar cuenta de la riqueza significativa del texto. En segundo lugar, el enfoque semiótico pretende integrar los puntos de vista posibles desde donde se pueda tener una comprensión cabal de todos los rasgos de los textos. Este punto de vista integrador lo lleva a ver el texto como un tipo específico de signo verbal (Petöfi, 1989: 518-519). De ahí, que su teoría comience con una reflexión sobre el signo a fin de precisar los conceptos y principios generales con los que se puede abordar el análisis de un texto. 
En la medida en que el concepto de texto y textualidad suponen la discusión y reformulación del triángulo semiótico, comenzaré por exponer la terminología que Petöfi introduce en este ámbito. Luego abordaré el concepto de texto y textualidad. Como se observará en ese momento, estos conceptos no son más que una reformulación a nivel del texto de la noción de signo.

\section{LA REFORMULACIÓN DEL TRIÁNGULO SEMIÓTICO}

La propuesta de Petöfi y de los otros coautores puede resumirse así: reemplazar la teoría triangular dominante del signo (significante, significado y referente) por una versión piramidal. La nueva figura implica, por un lado, una reorganización de los tres componentes tradicionales del signo. Petöfi complejiza la relación entre ellos al introducir subcomponentes en el plano del significante, significado y referente. Por otro lado, implica la introducción de un factor externo al signo mismo. Este nuevo elemento ocupa el lugar del vértice de la pirámide y no es otra cosa que el intérprete ${ }^{1}$ (Petöfi-Sözer, 1988: 443).

Lo más interesante de esta semiotic pyramid es la incorporación del sujeto como una instancia ajena a la estructura sígnica, pero sin la cual no habría relación de significación. El sujeto es el que instituye el signo, es decir, la relación entre significante, significado y referente:

Las flechas ${ }^{2}$ simbolizan que ambos, el significante y el significado y el signo son objetos (complejos) que dependen del intérprete (Petöfi-Sözer, 1988: 443).

En trabajos posteriores abandonó esta representación piramidal. Pero de ninguna manera quiere decir que eliminó al sujeto como la instancia fundante de la relación de significación. La estrategia utilizada por Petöfi es incorporar al intérprete en la estructura misma del signo. Concretamente en el componente mental del significante y del significado (stereotype knowledge). Por decirlo así: la instancia subjetiva, en la medida en que funda la significación, se vuelve un elemento interno del signo, es el medio en el que se lleva a cabo

\footnotetext{
1 Si bien Petöfi habla sólo de intérprete, con lo cual se pondría del lado de la recepción del signo, creo que puede interpretarse como la instancia de la enunciación, instancia que puede ser vista desde sus dos lados, a saber, desde el punto de vista de recepción (tú) o desde el punto de vista de la producción (yo).

${ }^{2}$ Se refiere al gráfico piramidal en donde desde los cuatro vértices de la base (un par expresa la complejización del significante y el otro el del significado) salen flechas que remiten al intérprete.
} 
la interrelación entre el vehículo significante, el significado y la realidad extralingüística.

La mediación de una instancia interpretativa es la razón por la que Petöfi busca un punto de vista integrador. En efecto, los signos verbales (y entre ellos los textos) para constituirse como tales remiten a una teoría de la subjetividad que debe explicar cuáles son las estructuras mentales que posibilitan la relación entre significado y significante. Cuando define el concepto de texto por referencia a la mente del intérprete (Petöfi-Sözer, 1988: 451) aparece de un modo muy claro esta teoría de la subjetividad supuesta en el proceso de significación. También asoma el trasfondo mentalista de su concepción del sujeto cuando redescribe uno de los componentes del significante y del significado como mental images (Petöfi, 1989: 509; Petöfi-Olivi, 1989: 194).

Una vez descrito el punto de vista teórico general desde donde redescribe el triangulo semiótico, voy a presentar brevemente los conceptos fundamentales de su propuesta teórica. Me parece que la figura piramidal es muy buena y por eso la voy a conservar en mi exposición. Las flechas que salen de la base de la pirámide, es decir, de lo que tradicionalmente es la relación entre significante, significado y referente, describen en mi lectura el eje de la deixis. La estructura del signo es, al mismo tiempo, un signo que apunta, señala e indica un centro de referencia, un eje de coordenadas espacio-temporales desde donde se instituye toda relación de significación. Este eje de coordenadas puede ser descrito o bien en términos de la instancia de la enunciación (yo-tú), o bien como el intérprete de Petöfi o, desde una perspectiva más filosófica, como el sujeto.

El signo supone la mediación de la subjetividad. La ventaja de la interpretación de las flechas como el eje de la deixis radica en que señalan necesariamente la mediación del sujeto, independientemente de cómo se lo describa teóricamente. Apuntan a una instancia subjetiva que es anterior a su descripción como mente, cerebro, sujeto histórico, sujeto trascendental o sujeto del discurso. Ciertamente que para Petöfi se trata de la mente, pero la estructura deíctica del signo es independiente de esta caracterización. La lectura mentalista del sujeto depende de la opción teórica elegida por Petöfi para dar cuenta del componente no-lingüístico de la significación.

El signo se define por la relación, mediatizada por un intérprete, entre el significante (significans) y el significado (significatum). En cada uno de estos componentes, Petöfi distingue a su vez dos subcomponentes. Por este motivo define al signo como una relación de cuatro elementos (Petöfi, 1989: 508). 


\subsection{Análisis del significante}

Desde el punto de vista del significante el signo está constituido por un subcomponente denominado vehiculum y otro llamado formatio.

El vehiculum da cuenta de los objetos reales (sonido, colores, tinta, etc.) que se utilizan como materia significante (Petöfi-Olivi, 1989: 191). Esta consideración es independiente del conocimiento estereotipado que tengamos de estos materiales. En el caso, por ejemplo, de los signos verbales ese vehiculum está constituido por los sonidos y no por los colores. Pero este aspecto del signo no designa la selección que cada cultura (el conocimiento estereotipado implicado en ella) hace de la totalidad de los sonidos para usarlo como significante.

Esta segunda consideración es lo que corresponde a la formatio. En efecto, desde este punto de vista el signo da cuenta del conocimiento que el intérprete tiene de esos objetos reales que se usan como medio significante. La mediación cognitiva del intérprete es lo que distingue la formatio del vehiculum: mientras que éste pertenece al plano de la realidad extramental, la formatio ${ }^{3}$ son imágenes mentales que surgen en el intérprete (Petöfi, 1989: 509).

\subsection{Análisis del significado}

El significado se desdobla en dos subcomponentes. El criterio de distinción es el mismo que Petöfi usa en el significante, a saber, la ausencia o la mediación cognitiva del intérprete. El relatum expresa el primer aspecto y el sensus el segundo.

La noción de relatum ${ }^{4}$ es paralela a la de vehiculum. Expresa lo que tradicionalmente se denominaba «referente», a saber, la realidad extrasemióti-

${ }^{3}$ Petöfi-Olivi (1989: 192-193) introduce en la formatio una nueva distinción: a) la figura, que expresa la información y el conocimiento del vehículo en cuanto objeto físico (por ejemplo: la figura en un texto sería los diferentes tipos de letras, colores, etc.) y b) la notatio, que da cuenta del conocimiento del vehículo en cuanto objeto semiótico (por ejemplo: si en un texto hay expresiones o palabras en diferentes lenguas, así como también el modo de cómo esas expresiones están organizadas desde un punto de vista sintáctico, morfológico y fonológico).

4 En los tres artículos hay diferentes nombres para este aspecto del significado. Sigo la terminología introducida en Petöfi-Olivi (1989) por ser el último artículo. En Petöfi-Sözer (1988: 443) se lo denomina «objeto» y en Petöfi (1989: 508) se llama a esta dimensión del significado correlatum. Pero en este artículo también habla del relatum. La distinción entre uno y otro término es la siguiente: el término correlatum lo restringe para los signos verbales elementales (como las palabras); en cambio usa el término 
ca o el conjunto de objetos y estados de cosas (states of affairs) a los que el signo remite (Petöfi-Olivi, 1989: 191-192). Es interesante subrayar que para Petöfi el referente queda incorporado al significado. La realidad no es algo ajeno al proceso semiótico, sino, por el contrario, es su polo objetivo.

El concepto de sensus es análogo al de formatio. Da cuenta de aquella dimensión del significado que corresponde al conocimiento estereotipado que el intérprete tiene del relatum (objetos y estados de cosas). Por ello tiene un estatus cognitivo, son imágenes mentales ${ }^{5}$ (Petöfi, 1989: 509).

\subsection{El concepto de interpretación}

Este término designa la operación fundamental de la comunicación en las lenguas naturales (Petöfi-Sözer, 1988: 445). El tratamiento de la interpretación se articula en tres aspectos: el objeto, la meta y los tipos. Expondré brevemente el primero de estos aspectos.

La interpretación puede tener dos posibles objetos ${ }^{6}$ o bien se ocupa de la relación entre significante y significado; o bien se interesa por la inserción (embeddedness) del signo en diferentes contextos. A la primera la llama construcción y a la segunda la denomina interpretación funcional. Estas dos posibilidades interpretativas pueden ser vistas desde un punto de vista estático (también llamado estructural) o desde una perspectiva dinámica (también llamada procedural). El enfoque estructural responde a la pregunta sobre los

relatum para los signos verbales compuestos (compounds). La razón es que estos últimos signos refieren un objeto en una situación de comunicación dada. También aquí existen, por un lado, los relata (término paralelo a correlata) —en tanto objetos y estados de cosas - y la imagen mental de ellos (el plano del conocimiento) que surge en el intérprete. A esta imagen mental la denomina el modelo (Petöfi, 1989: 511-512).

${ }^{5}$ En Petöfi-Olivi (1989: 193-194) se introduce una distinción dentro del sensus: a) el dictum vs. signum-internal relatum. Esta oposición se funda en la posibilidad de distinguir en un enunciado entre el contenido proposicional (dictum) y la posible interpretación que se le puede asignar al mismo contenido en diferentes contextos comunicativos. El dictum es el contenido semántico invariable, por ello puede ser formulado de diversas maneras, con distintas palabras. El signum-internal relatum es la interpretación que el dictum puede asumir en diferentes contextos o cotextos. Y b) sensus conceptual vs. sensus no conceptual. Según Petöfi el sentido no-conceptual son, por ejemplo, las experiencias relativas al vehículo. El sentido conceptual, por el contrario, puede asumir dos modalidades: la no verbal (como, por ejemplo, la imagen mental de la descripción de un paisaje que se hace en un texto) o la verbal (el conjunto verbal de propiedades de ese mismo paisaje).

${ }^{6}$ En Petöfi-Olivi (1989: 196-199) se afina aún más cada una de las distinciones aquí introducidas. Se agrega subcomponentes para cada una de ellas. No las menciono porque la distinción fundamental entre construcción vs. función y los dos puntos de vistas, estructural $v s$. procedural se mantienen idénticos. Sólo se trata de distinciones sutiles que poco agregan a la teoría general. 
tipos de elementos que constituyen la construcción o funcionalidad. En cambio, el punto de vista procedural es una descripción genética del signo, es decir, remite el signo al sistema de creencias del intérprete, en el que éste ocupe la posición de productor o de receptor (Petöfi-Sözer, 1988: 445).

Menciono simplemente, a continuación, los otros dos aspectos de la interpretación estudiados por Petöfi: las metas (goals) pueden ser descriptivas, explicativas, evaluativas y argumentativas (Petöfi-Olive, 1989: 195); pudiéndose combinar cada una de ellas con las otras. Por lo que habría tres tipos de interpretación: la natural, la teórica y la automática.

\section{LA SEMIÓTICA TEXTUAL}

El texto es un tipo de signo. La pregunta que surge entonces es ¿a qué tipo de signo corresponde? La respuesta de Petöfi es la siguiente: el texto es un signo verbal. Ello significa que el vehículo está constituido por elementos lexicales sonoros o escritos. Pero aquí no se agota la definición. Es necesario que ese signo verbal sea considerado por un intérprete como una totalidad significativa que cumple una determinada función comunicativa (Petöfi-Sözer, 1988: 541):

Para un intérprete, un objeto verbal se cualifica como texto si puede considerarlo como un objeto conectado y completo que satisface una intención dada en un contexto comunicativo dado (Petöfi, 1989: 511).

De acuerdo con esta definición la textualidad no es una propiedad inherente al signo verbal mismo (Petöfi-Olivi, 1989: 511). El criterio de textualidad es extra-textual (Petöfi, 1989: 511). Podría decirse que el parámetro último de la textualidad de un signo viene dado por su referencia a la competencia modal de un intérprete. Sin la mediación del sistema de creencias de los intérpretes no puede decirse que una determinada secuencia significativa sea un texto. Esta definición modal de la textualidad es la que aparece en el siguiente artículo:

Un productor o receptor considera que un objeto verbal es un texto si cree que este objeto verbal es una totalidad [entirety] conectada y completa que satisface una intención comunicativa real o asumida en una situación de comunicación real o asumida (Petöfi-Olivi, 1989: 191; el subrayado es mío).

Si el texto es un tipo específico de signo verbal, entonces todos los componentes mencionados en el punto anterior intervienen en su caracterización. 
Los componentes semióticos del texto son los siguientes ${ }^{7}$ : a) el vehiculum que expresa el texto en cuanto objeto físico; b) la formatio que es la imagen mental del vehículo (que adopta una constitución gráfica, prosódica, sintáctica y poético-retórica, como puede verse en Petöfi, 1989: 513, donde lo llama el significante); c) el significado en tanto dictum y en tanto relatum; d) el modelo de interpretación que se construye a partir del significante, el dictum y el relatum (es el sistema de conocimiento sobre los estados de cosas que el intérprete acepta como un interpretamentum posible) y e) Interpretamentum/interpretamenta, que es la realidad extralingüística, el relatum asignado al texto más su contexto de producción en un contexto dado de interpretación por medio de un modelo de interpretación.

La interpretación de un texto da lugar a tres conceptos fundamentales que están interrelacionados: construcción, configuración y constitución. La construcción manifiesta la propiedad inherente de los textos de expresar mediante la interpretación la realidad extralingüística (a set of states of affairs). Esta propiedad supone que la realidad posee una estructura o configuración específica ${ }^{8}$. La constitución, por su parte, da cuenta del componente verbal del texto que, precisamente, posibilita la construcción de la realidad (Petöfi, 1989: 512; Petöfi-Olivi, 1989: 203).

De estos tres aspectos de la interpretación textual Petöfi estudia detalladamente los problemas relativos a la constitución. No obstante, señala que el objeto primario de la interpretación es la construcción (Petöfi, 1989: 513), es decir, la relación entre el material verbal y la realidad extralingüística. El sentido de esta afirmación es el siguiente:

En orden a ser capaces de interpretar un texto, debemos primero (re)construir el fragmento del mundo (en otras palabras el universo relatado) que está manifiesto implícitamente en el texto a ser interpretado. Este universo relatado hace posible construir modelos de interpretación, con la ayuda de los cuales podemos asignar una interpretación /interpretaciones (en nuestra terminología un interpretamentum/interpretamenta) al texto a ser interpretado (Petöfi-Sözer, 1988: 453).

${ }^{7}$ En Petöfi-Olivi (1989: 201-202) se afinan aún más los elementos semióticos del texto de acuerdo a los nuevos subcomponentes que introduce. La exposición más detallada mantiene estos elementos esenciales que se mencionan aquí.

${ }^{8}$ En Petöfi-Sözer (1988: 452) se matiza esta afirmación de neto corte ontológico: «...la configuración remite a una propiedad inherente a la serie de estados de cosas (si tal serie tiene de alguna manera una propiedad inherente)...». 
El concepto fundamental que pertenece al dominio de la construcción es el de coherencia (Petöfi-Olivi, 1989: 204). Este término expresa precisamente el trabajo de reconstrucción de la realidad extralingüística (universo relatado) mediante modelos de interpretación. Estos modelos no son otra cosa que representaciones de la configuración de la realidad ${ }^{9}$ (Petöfi-Sözer, 1988: 454). Petöfi distingue dos tipos de coherencia: explícita cuando la interpretación asignada al texto representa todos los estados de cosas; latente cuando la interpretación no contiene todos los estados de cosas, sino que tienen que ser inferidos (Petöfi-Olivi, 1989: 204).

Para finalizar con la teoría semiótica de Petöfi quisiera hacer una breve alusión al concepto que tradicionalmente se le contrapone al de coherencia. Me refiero a la cohesión. Para Petöfi es un término que pertenece a la constitución textual ${ }^{10}$. La cohesión textual designa la continuidad en el plano del significado del texto y se contrapone a la conectividad que es la continuidad del significante (Petöfi-Sözer, 1988: 453).

Como se puede deducir de lo anteriormente expuesto, la cohesión semántica de un texto presupone la coherencia de la interpretación y la unidad de la realidad. Podría decirse que hay un isomorfismo estructural entre el mundo (realidad extralingüística), los modelos mentales que el intérprete asigna al texto y la continuidad semántica de los enunciados. Ciertamente que esta afirmación es un presupuesto de la teoría que tiene que ser investigado y fundamentado. Por eso, creo que no basta simplemente la consideración semiótica para fundamentar una teoría de la coherencia textual. Es necesario salirse de los límites del lenguaje — hecho que J. Petöfi reconoce explícitamente- - y acudir a consideraciones filosóficas que fundamenten esta posición.

Para finalizar, dejo abierta una posible respuesta a esta cuestión del isomorfismo entre realidad, lenguaje y mente. Dicho muy brevemente: creo que la fenomenología de la comprensión textual de M. Scherner (1974, 1984,

9 Petöfi introduce dos términos que describen los aspectos configurativos de la realidad extralingüística. Ellos son: constringencia (constringency) e integridad (integrity). Ambos términos son análogos en el plano real de las nociones pertenecientes a la constitución textual de continuidad (continuity) y completud (completeness). Petöfi los explica así: la constringencia describe el hecho de que la realidad posee elementos conectados en un único continuum. Este aspecto de la configuración sólo es relevante para el intérprete. La integridad da cuenta del carácter total de la realidad. También esta propiedad está vinculada a las expectativas del intérprete (Petöfi-Olivi, 1989: 203-204).

${ }^{10}$ Los problemas de la constitución se organizan en torno a dos pares de opuestos: a) textualidad y composición y b) continuidad y completud (completeness). La cohesión pertenece a este segundo grupo. Es un fenómeno de continuidad semántica. 
1998) ofrece una solución no-mentalista al problema y llena la laguna dejada de lado por J. Petöfi en la medida en que a) reconoce a la subjetividad humana como el criterio de textualidad último, entendida no como mente, sino como diversos horizontes de comprensión; b) asume la ontología de W. Schapp (1985), para quien el hecho ontológico primitivo no son los datos de los sentidos, sino las historias en las que las cosas y nosotros estamos envueltos (in Geschichten verstrickt) y c) el isomorfismo estructural no es otra cosa que la continuidad entre las historias constitutivas de la realidad, la trama significativa del lenguaje (Sprache als Text) y un sujeto que despliega diversos horizontes de comprensión.

\section{REFERENCIAS BIBLIOGRÁFICAS}

NAGEL, TH. (1996). Una visión desde ningún lugar. México: FCE.

PetÖFI, J. S. (1989). «Constitution and Meaning: A Semiotic Text-Theoretical Approach». En Text and Discourse Connectedness, M.E. Conte, J.S. Petöfi y E. Sözer (eds.), 507-542. Amsterdam-Philadelphia: John Benjamins Publishing Co.

PetöFi, J. S. y Olivi, T. (1989). «Understunding Literary Texts. A Semiotic Textological Approach». En Comprehension of Literary Discourse. Results and Problems of Interdisciplinary Approaches, D Meutsch y R. Viehoff (eds.), 191-225. Berlin-New York: Walter de Gruyter.

PetöFi, J. S. y Sözer, E. (1988). «Static and Dynamic Aspects of Text Constitution». EnText and Discourse Constitution. Empirical Aspects, Theoretical Approaches, J.S. Petöfi (ed.), 440-477. Berlin-New York: Walter de Gruyter.

Ricoeur, P. (1998). Teoría de la interpretación. Discurso y excedente de sentido. México: Siglo XXI.

- (2001). Del texto a la acción. Ensayos de hermenéutica II. México: Fondo de Cultura Económica.

SchaPP, W. (1985). In Geschichten verstrickt. Zum Sein von Mensch und Ding. Frankfurt am Main: Vittorio Klostermann.

SCHERNER, M. (1974). «Horizont». En Historisches Wörterbuch der Philosophie, J. Ritter (hrsg.), Band 3, 1.187-1.206. Darmstadt: Wissenschaftliche Buchgesellschaft. 
- (1984). Sprache als Text. Ansätze zu einer sprachwissenschaftlic begründeten Theorie des Textverstehens. Forschungsgeschichte-ProblemstellungBeschreibung. Tübingen: Max Niemeyer.

- (1998). «Text». En Historisches Wörterbuch der Philosophie, J. Ritter (hrsg.), Band 10, 1.038-1.043. Darmstadt: Wissenschaftliche Buchgesellschaft. 